\title{
Viral induction of a chronic asthma phenotype and genetic segregation from the acute response
}

\author{
Michael J. Walter, ${ }^{1}$ Jeffrey D. Morton, ${ }^{1,2}$ Naohiro Kajiwara, ${ }^{1}$ Eugene Agapov, ${ }^{1}$ \\ and Michael J. Holtzman ${ }^{1,2,3}$ \\ ${ }^{1}$ Pulmonary and Critical Care Medicine, Department of Medicine, \\ ${ }^{2}$ Program in Immunology, and \\ ${ }^{3}$ Department of Cell Biology and Physiology, Washington University School of Medicine, St. Louis, Missouri, USA
}

Paramyxoviral infections cause most of the acute lower respiratory tract illness in infants and young children and predispose to the development of chronic wheezing, but the relationship between these short- and long-term viral effects are uncertain. Here we show that a single paramyxoviral infection of mice (C57BL6/J strain) not only produces acute bronchiolitis, but also triggers a chronic response with airway hyperreactivity and goblet cell hyperplasia lasting at least a year after complete viral clearance. During the acute response to virus, same-strain ICAM-1-null mice are protected from airway inflammation and hyperreactivity despite similar viral infection rates, but the chronic response proceeds despite ICAM-1 deficiency. Neither response is influenced by IFN- $\gamma$ deficiency, but the chronic response is at least partially prevented by glucocorticoid treatment. In contrast to viral infection, allergen challenge caused only short-term expression of asthma phenotypes. Thus, paramyxoviruses cause both acute airway inflammation/hyperreactivity and chronic airway remodeling/hyperreactivity phenotypes (the latter by a hit-and-run strategy, since viral effects persist after clearance). These two phenotypes can be segregated by their dependence on the ICAM-1 gene and so depend on distinct controls that appear critical for the development of lifelong airway diseases such as asthma.

J. Clin. Invest. 110:165-175 (2002). doi:10.1172/JCI200214345.

\section{Introduction}

The traditional scheme of asthma pathogenesis is based on a relative increase in Th2 cellular responses in combination with a decrease in Th1 responses. The consequent alteration in cytokine milieu, with excess Th2 products (e.g., IL-4, IL-5, and IL-13) and decreased Th1 products (e.g., IFN- $\gamma$ and IL-12) is predicted to drive the asthma phenotype. Evidence for such a shift in the Th1/Th2 balance derives from studies of asthma in cellular and murine models, where Th cell polarization and allergen dependence of Th2 responses are most clearly defined, and from human studies that profile cytokine production and immune cell infiltrate. Thus, in the murine system, IL-4, IL-5, IL-9, and IL-13 promote Th 2 cell differentiation and B cell-dependent $\operatorname{IgE}$ production, tissue eosinophilia, goblet cell hyperplasia, and airway hyperreactivity $(1,2)$. Furthermore, these responses are downregulated by Th 1 cytokines such as IFN- $\gamma$ and IL-12 and are inversely correlated with the

Received for publication October 4, 2001, and accepted in revised form June 4, 2002.

Address correspondence to: Michael J. Holtzman, Washington University School of Medicine, Campus Box 8052,

660 South Euclid Avenue, St. Louis, Missouri 63110, USA. Phone: (314) 362-8970; Fax: (314) 362-8987;

E-mail: holtzmanm@msnotes.wustl.edu.

Michael J. Walter and Jeffrey D. Morton contributed equally to this work.

Conflict of interest: No conflict of interest has been declared. Nonstandard abbreviations used: Sendai virus (SeV); $50 \%$ egg infectious dose $\left(\mathrm{EID}_{50}\right)$; periodic acid-Schiff (PAS); enhanced pause (Penh); ovalbumin (Ova). level of Th1 cell responses (3-6). In humans, asthma is tied to this paradigm by association with atopy and concomitant increases in the production of IgE and Th2 cell cytokines (7-9). Recent studies also provide evidence of genetic linkage to polymorphisms in the $I L-4, I L-4$ receptor, and $I L-13$ genes (10). Similarly, eosinophils and mast cells are characteristic of asthmatic airway inflammation $(11,12)$ and may act as critical effector cells, at least under some circumstances $(13,14)$.

However, several lines of evidence in model systems and in humans raise questions regarding the Th2 hypothesis as a complete explanation for asthma. For example, Th1 and antigen-specific Th2 cells may be necessary for initiating the allergic response even in mouse models of asthma $(15,16)$. Furthermore, endpoints of the allergic response, such as airway hyperreactivity and mucus production, may develop without IgE production and eosinophil influx (17-19). In some cases, airway reactivity may be dissociated from eosinophilic inflammation based on genetic background $(20,21)$. In fact, in human subjects, the development of allergy and asthma are often dissociated as well (22), and linkage to candidate genes for atopy has not been found in large population studies (23). Moreover, treatment aimed at selective blockade of Th2 pathways has not yet proven to be efficacious in asthma (24). Nonetheless, these discrepancies are generally ascribed to the complexity of the allergic response, so that other features of the response may still lead to the asthma phenotype (25). Even given this diversity, however, the Th2 hypothesis does not take into account a 
newly described yet invariant feature of asthma: an intrinsic abnormality in cellular programming of the airway epithelium toward an anti-viral Th1 response (26). In particular, airway epithelial cells are specially programmed with anti-viral networks, and the behavior of these cells in asthma resembles a persistent antiviral response (27-31). It is also not certain how the Th2 hypothesis reconciles its insights into the allergic response - a short-term response - with the development of a lifelong disease.

In that context, a relationship between viral infection and the development of chronic inflammatory disease has been proposed for diverse clinical syndromes, but the mechanistic basis for this relationship is still uncertain. Relevant to asthma, paramyxoviral infections are the leading cause of lower respiratory tract illness in infants and young children $(32,33)$, and children with clinically significant viral bronchiolitis appear to be marked for the subsequent development of a chronic wheezing illness that is independent of allergy (34). Presumably paramyxoviral infection triggers an abnormal host response, since paramyxoviruses (and other respiratory RNA viruses) are not thought to persist in airway tissue as an ongoing stimulus of chronic respiratory disease (35). In either case (i.e., with or without viral persistence), the role of specific host factors in the development of acute or chronic wheezing or lifelong asthma still remains to be determined.

To better define viral and host factors in the development of the asthma phenotype, we took advantage of a mouse model of paramyxoviral bronchiolitis with acute pathology similar to the human condition (31). Thus, mouse parainfluenza virus type 1 (Sendai virus; $\mathrm{SeV}$ ) at proper inoculum causes infection limited to the airway mucosa and inflammation largely restricted to peribronchial/bronchiolar tissues. We reasoned that inhibition of the acute inflammatory response could be achieved by targeted disruption of airway epithelial immune-response genes. These genes form a network that is directly induced by viral replication and is dominated by an array of IFN-responsive genes $(27,29,31)$. Among candidate genes that might mediate immune cell traffic, ICAM- 1 is the predominant determinant for adhesion of immune cells (especially $\mathrm{T}$ cells) to epithelial cells in vitro $(28,36,37)$. Indeed, in the present experiments conducted in vivo, we found that ICAM-1 expression is induced primarily on host airway epithelial cells by viral infection and is necessary for full development of acute inflammation and concomitant postviral airway hyperreactivity. Unexpectedly, however, we also found that primary viral infection causes a persistent asthma phenotype (i.e., airway hyperreactivity, goblet cell hyperplasia, and mucin production) despite ICAM-1 deficiency, and this phenotype is maintained despite clearance of virus. This phenotype is also inducible by allergen challenge, but in this case, the phenotype resolves spontaneously with time. In the context of previous data, the findings establish the capacity of a single paramyxoviral infection to cause both acute and chronic manifestations of the phenotype for hypersecretory airway disease and define the relevance of specific host defense genes in moderating the acute, but not necessarily the chronic, phenotype. In addition, the results provide initial evidence of the capacity for nononcogenic riboviruses (i.e., paramyxovirus) to irreversibly reprogram host cell behavior in a manner previously restricted to oncogenic DNA viruses $(38,39)$. These findings therefore raise the possibility that asthma not only resembles a persistent anti-viral response $(30,31)$ but may even be caused by such a response, and so provide the experimental link between paramyxoviral infection in infancy with subsequent asthma in childhood and perhaps adulthood.

\section{Methods}

Mouse generation and housing. Wild-type C57BL/6J and same-strain IFN- $\gamma$-null mice were obtained from The Jackson Laboratory (Bar Harbor, Maine, USA) (40). Same-strain ICAM-1-null mice were a generous gift from J.-C. Gutierrez-Ramos (Millennium Pharmaceuticals Inc., Cambridge, Massachusetts, USA) directly and via The Jackson Laboratory (41). IFN- $\gamma$ - and ICAM-1-null mice were backcrossed for nine and ten generations, respectively, onto the C57BL/6J strain. The ICAM-1-null mice are interrupted in ICAM-1 gene exon 4 to avoid generation of alternatively spliced isoforms that may still interact with lymphocyte function antigen-1 (42). Thus, anti-ICAM-1 mAb 3E2 recognizes all five ICAM- 1 isoforms and does not detect ICAM-1 in this strain (ref. 41 and data not shown). Mice were maintained under pathogen-free conditions for study at 7-9 weeks of age. Experimental manipulations were performed in a class II laminar flow hood. Sentinel mice and experimental control mice were handled identically to inoculated mice and exhibited no serologic or histologic evidence of exposure to 11 rodent pathogens (including $\mathrm{SeV}$ ).

Viral inoculation and monitoring. After ketamine/ xylazine anesthesia, mice were inoculated intranasally with the indicated dose $(50 \%$ egg infectious dose, $\mathrm{EID}_{50}$ ) of $\mathrm{SeV}$ (Fushimi strain) or with UV-inactivated $\mathrm{SeV}$ in $30 \mu \mathrm{l} \mathrm{PBS}$. The viral expression level in lung tissue was monitored by immunostaining and Western blotting with anti-SeV Ab (31), viral plaque assay (43), and real-time quantitative RT-PCR using a fluorogenic probe/primer combination for $\mathrm{SeV}$ nucleocapsid protein RNA (nucleotides 519-587 in GenBank accession $\mathrm{M} 30202$ ) according to the manufacturer's protocol (PE Biosystems, Foster City, California, USA). Lung RNA was extracted with TRIzol (Invitrogen Corp., Grand Island, New York, USA) and the RNeasy mini kit (QIAGEN Corp., Valencia, California, USA). The extracted RNA was then subjected to RT-PCR using the TaqMan One-Step system (PE Biosystems) to detect viral negative- and positive-strand RNA. Synthetic RNA standards for nucleocapsid protein and control GAPDH were generated from portions of the nucleocapsid protein gene (nucleotides 10-620) and GAPDH gene 
(nucleotides 37-910) cloned into pCR2.1 (Invitrogen Corp., Carlsbad, California, USA) and were in vitro transcribed using T7 MEGAscript (Ambion Inc., Austin, Texas, USA). Standards were purified by TRIzol extraction, DNase treatment (three rounds), RNeasy mini kit preparation (three rounds), and phenol extraction, and then run in duplicate serial dilutions to construct standard curves and calculate the copy number of virus-specific RNA in experimental samples.

Histochemistry. Mouse lung (at $25 \mathrm{~cm} \mathrm{H}_{2} \mathrm{O}$ pressure) was fixed in $10 \%$ buffered formalin, dehydrated in ethanol, embedded in paraffin, and cut into 5 - $\mu \mathrm{m}$-thick sections. To detect ICAM-1, tissue sections were blocked with $5 \%$ nonimmune goat serum and then incubated sequentially with hamster anti-mouse ICAM-1 IgG $\mathrm{mAb}(2 \mu \mathrm{g} / \mathrm{ml}$ of clone 3E2 from Pharmingen, San Diego, California, USA), biotinylated goat anti-hamster $\operatorname{IgG}(7.5 \mu \mathrm{g} / \mathrm{ml})$, streptavidin-conjugated horseradish peroxidase, and 3,3'-diaminobenzidine chromogen (Vector Laboratories Inc., Birmingham, California, USA). Sections were also immunostained for MUC5AC mucin and underwent amylase digestion and Alcian blue/periodic acid-Schiff (PAS) staining as indicators of mucus production and corresponding levels of goblet cells (44). For MUC5AC immunostaining, tissues were blocked with mouse IgG (Vector Laboratories Inc.) and then incubated with mouse anti-human MUC5AC $\mathrm{mAb} 45 \mathrm{M} 1(2 \mu \mathrm{g} / \mathrm{ml}$; Lab Vision Corp., Fremont, California, USA). Tissue sections were counterstained with hematoxylin, dehydrated in graded ethanol, and mounted for photomicrography and quantification of reporter by cell counting (cells per $\mathrm{mm}$ of basement membrane), area of epithelium (percentage of total epithelial area calculated using Image-Pro Express version 4; Media Lybernetics, Carlsbad, California, USA), and epithelial staining intensity (calculated using Optimas version 5; Optimas Corp., Bothell, Washington, USA) as described previously $(30,31)$.

Bronchoalveolar lavage fluid analysis. Bronchoalveolar lavage was performed via tracheal cannulation with an aliquot of $0.8 \mathrm{ml}$ of sterile PBS with $2 \%$ FBS. Each sample was subjected to hypotonic lysis, cytospin centrifugation, and Wright-Giemsa staining, and was then used for total and differential cell counts.

Airway reactivity measurements. Airway reactivity to aerosolized methacholine was determined using a single-chamber whole-body plethysmograph and BioSystem XA version 1.5.7 software (Buxco Electronic Inc., Sharon, Connecticut, USA) to derive values for enhanced pause (Penh) as described previously (45). Mice were placed in the plethysmograph for a 5-minute acclimatization interval, followed by 5 -minute acquisition intervals before (baseline Penh) and after 3-minute exposure to nebulized vehicle (PBS) or doubling concentrations of methacholine $(5-160 \mathrm{mg} / \mathrm{ml})$ delivered from a Collison 6 jet nebulizer (BGI Inc., Waltham, Massachusetts, USA). Allergen challenge. C57BL/6J mice were sensitized and then challenged with antigen using a method modified from one described previously (46). Mice were immunized by intraperitoneal injection of ovalbumin (Ova; $8 \mu \mathrm{g}$ ) adsorbed to aluminum hydroxide gel (1 $\mathrm{mg}$ ) in $0.5 \mathrm{ml}$ PBS at 3 weeks before challenge (study day -21), and were given an identical booster immunization 2 weeks before challenge (day-14). Mice were challenged with PBS or Ova $(2 \mathrm{mg})$ in PBS $(50 \mu \mathrm{l})$ given intranasally as described above for viral inoculation. Challenges were performed with intranasal PBS or Ova either twice (12 hours apart) on day 0 (for a total of two challenges) or twice on day 0 and again once on days 1 and 2 (for a total of four challenges). On days 3 , 21 , and 77 after initial challenge, all mice were assessed for airway reactivity and goblet cell hyperplasia as described above.

Statistical analysis. Values for bronchoalveolar lavage fluid cell counts, weight losses, Western blots, and viral titers were analyzed using the unpaired Student $t$ test. Values for Penh and histochemistry of mouse tissues were analyzed using a one-way ANOVA for a factorial experimental design. If significance was achieved by one-way analysis, comparison of means after ANOVA was performed using Scheffe's $F$ test. The significance value for all analyses was 0.05 .

\section{Results}

ICAM-1-null mice are protected against airway inflammation after $\mathrm{SeV}$ bronchiolitis. Initial experiments indicated that $\mathrm{SeV}$ inoculation with 50-50,000 EID $_{50}$ caused a spectrum of illness ranging from no detectable effect (at 50 $\mathrm{EID}_{50}$ or UV-inactivated $\mathrm{SeV}$ at any inoculum) to reversible bronchiolitis $\left(\right.$ at 5,000 $\mathrm{EID}_{50}$ ) to lethal bronchopneumonia (at 50,000 $\mathrm{EID}_{50}$ ) in the C57BL/6J genetic background (ref. 31 and data not shown). We therefore used $\mathrm{SeV}$ inoculation at 5,000 $\mathrm{EID}_{50}$ for further experiments aimed at modeling viral bronchitis/bronchiolitis in humans. With this inoculum, $\mathrm{SeV}$ replication and induction of ICAM-1 expression were colocalized predominantly to bronchiolar epithelium (Figure 1a). Wild-type and ICAM-1-null mice responded to this level of infection with immune cell infiltration confined to sites of viral replication, but ICAM-1-null mice responded with fewer immune cells, especially neutrophils and lymphocytes (Figure 1, b and c). This phenotypic pattern is consistent with in vitro findings, i.e., in airway epithelial cell monolayers, where ICAM-1 gene expression is inducible by paramyxoviral infection and is required for leukocyte adhesion and transmigration $(28,29,36,37,47)$. These findings are also consistent with evidence of decreased inflammation after loss of ICAM-1 in several other models, including allergen challenge (48). However, others report little change in neutrophil influx induced by Streptococcus pneumoniae or Klebsiella pneumoniae (49, 50), perhaps reflecting alternative mechanisms for immune cell recruitment and/or activation in response to bacterial infection in the lung.

The blunted inflammatory response in ICAM-1-null mice was beneficial to the host since this cohort experienced less weight loss after bronchiolitis (Figure 2a) 


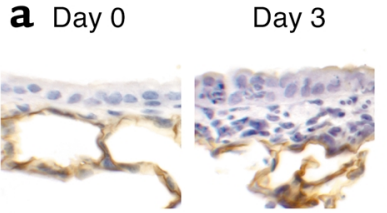

b

Day 3
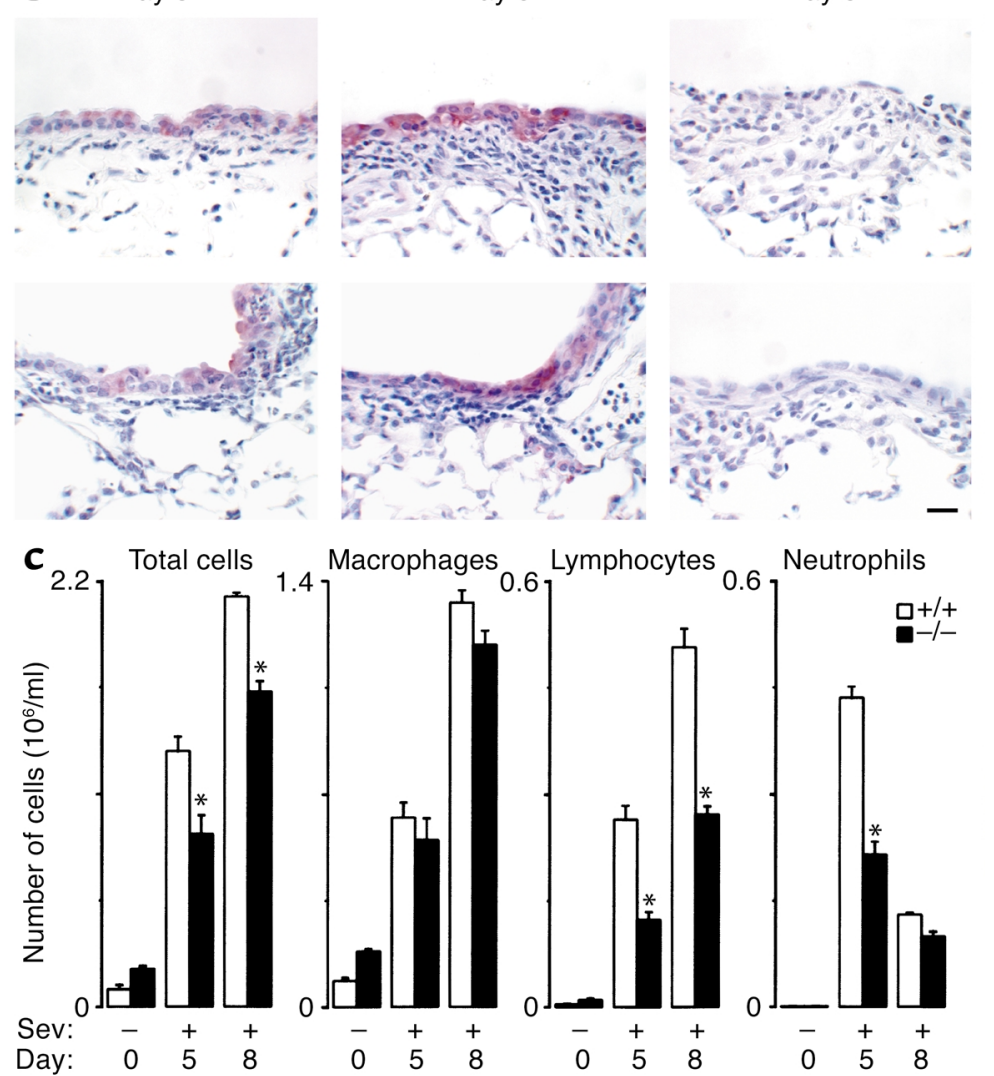

Neutrophils

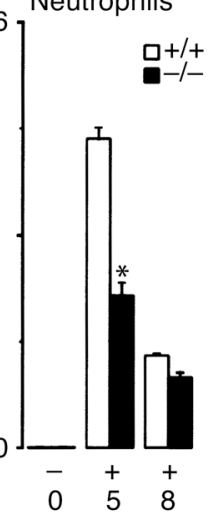

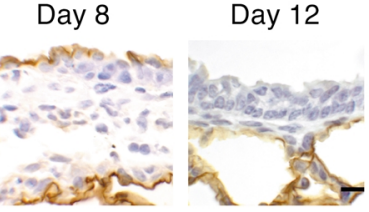

Day 8

\section{Figure 1}

ICAM-1 deficiency protects against virus-induced inflammation. Wild-type (+/+) and ICAM-1-null (-/-) mice were inoculated with $\mathrm{SeV}\left(5,000 \mathrm{EID}_{50}\right)$ and analyzed as follows. Lung sections were immunostained with anti-ICAM-1 (a) or anti-SeV Ab (b) and counterstained with hematoxylin on the indicated postinoculation days. Representative photomicrographs are shown for each genotype (four mice/genotype). Wildtype mice inoculated with PBS or SeV-UV revealed alveolar but not conducting airway epithelial staining for ICAM-1, and incubation of lung tissue with control nonimmune IgG resulted in no signal above background in either genotype (data not shown). Similarly, ICAM-1-null mice exhibited no detectable ICAM-1 staining above background (data not shown). Bar, 20 $\mu \mathrm{m}$. (c) Bronchoalveolar lavage fluid was subjected to total and differential cell counts. Values represent mean \pm SEM for four mice. For $\mathbf{a}-\mathbf{c}$, values obtained from $+/+$ and $-/$ - cohorts inoculated with PBS or UVinactivated $\mathrm{SeV}$ were no different from preinoculation values (data not shown). *Significant decrease compared with the wild-type cohort. and lower mortality rates after $\mathrm{SeV}$ bronchopneumonia (data not shown). In addition, the decrease in airway inflammation did not appear to hamper host defense, since initial viral infection rate and subsequent clearance was not significantly altered in ICAM-1-null versus wild-type control mice (Figure 2, b-d). Clearance by 12-21 days after $\mathrm{SeV}$ infection is consistent with previous reports that assess viral titer by endpoint titration in embryonated hen eggs (51-53), but the present data using real-time RT-PCR also provides evidence against persistence of viral genome in the host tissue as mutant quasispecies of virus (54).

ICAM-1-null mice are protected against acute but not chronic airway byperreactivity after $\mathrm{SeV}$ bronchiolitis. We have long proposed that airway inflammation may lead to airway hyperreactivity (55), so we determined whether ICAM-1-null mice (which are relatively protected from virus-induced airway inflammation) are also protected from postviral hyperreactivity. For these experiments, we used whole-body barometric plethysmography to measure Penh as an index of airway obstruction at baseline and after methacholine challenge in wild-type and ICAM-1-null mice inoculated with SeV, UV-inactivated $\mathrm{SeV}$, or vehicle alone. In this setting, we found slightly increased baseline Penh and airway reactivity by 7 days after inoculation with $\mathrm{SeV}$ in both types of mice (Figure 3). Baseline Penh returned to normal in both types of mice by 14 days after inoculation, but airway reactivity was increased markedly by this time in wild-type mice. Moreover, the development of postviral hyperreactivity at this timepoint and at 21 days after inoculation was significantly diminished in ICAM-1-null mice. Methacholine-induced increases in Penh were rapidly and fully reversible by treatment with inhaled albuterol, and so were consistent with airway smooth muscle contraction and consequent bronchoconstriction (data not shown).

These findings linked virus-inducible inflammation with hyperreactivity via the ICAM-1 gene during the first 21 days after infection, but continued monitoring indicated that hyperreactivity recurred at maximal levels by 77 days after infection in ICAM-1-null mice, and persisted throughout the monitoring period in wildtype mice (Figure 3). In fact, virus-inducible hyperreactivity proceeded unchanged for at least a year (see below). Thus, ICAM-1 deficiency protects to at least some degree against acute inflammation (maximal at 8 days) and subacute airway hyperreactivity (maximal 

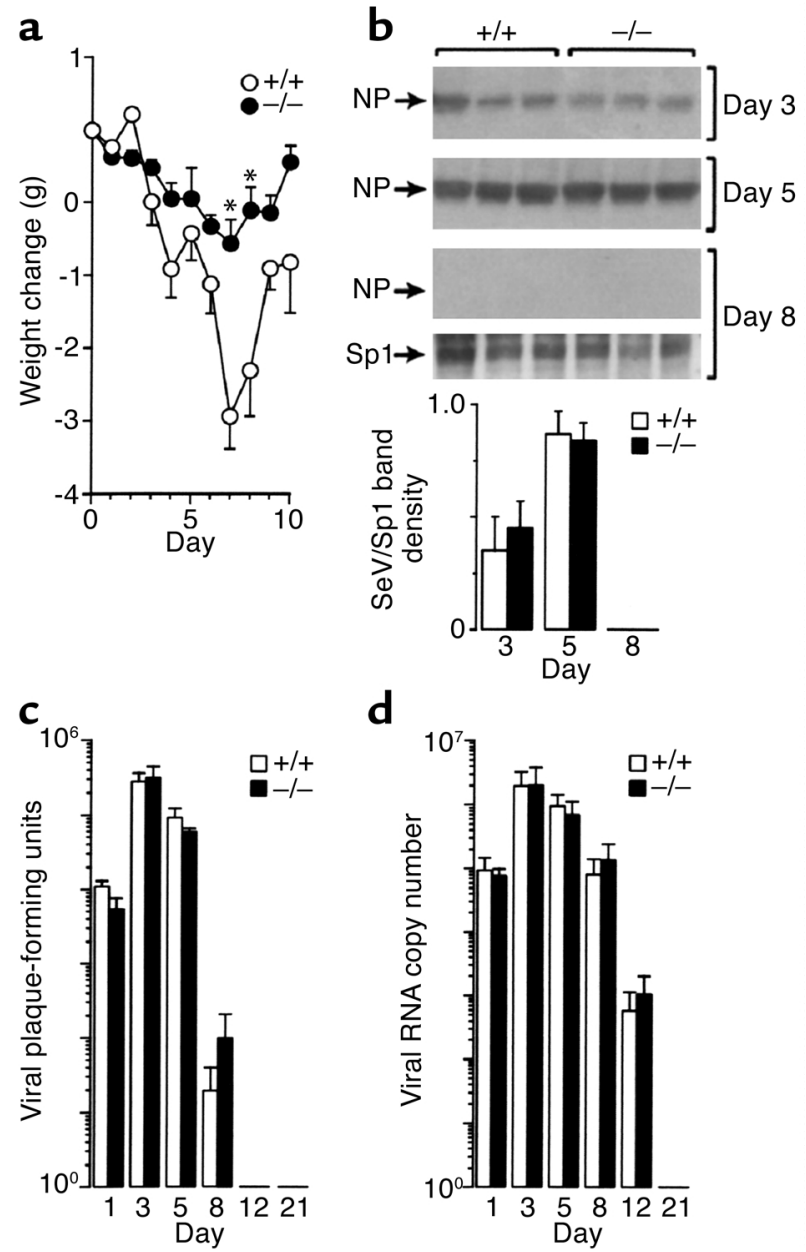

at 21 days) but does not protect at all against the chronic hyperreactivity (manifest at 77 days and longer) that develops in response to $\mathrm{SeV}$ infection in this genetic background. Many previous reports indicate that respiratory viral infection may transiently increase airway reactivity in animal models and humans (56), but the present findings indicate that viral infection may also permanently reprogram airway reactivity.

Chronic airway hyperreactivity is accompanied by airway remodeling after $\mathrm{SeV}$ bronchiolitis. Recognizing that the host epithelial cell is a primary target of viral infection, we next determined whether infection also resulted in persistent changes in epithelial behavior.

\section{Figure 3}

ICAM-1 deficiency protects against acute but not chronic airway hyperreactivity induced by viral infection. Wild-type or ICAM-1-null mice were assessed for airway reactivity to inhaled methacholine by measurements of Penh at the indicated times before and after inoculation with $\mathrm{SeV}\left(5,000 \mathrm{EID}_{50}\right)$ or an equivalent amount of SeV-UV. Values are provided for baseline (B) and after exposure to vehicle (V) or methacholine (doubling concentrations, 5-160 mg/ml), and each value represents mean \pm SEM of eight to nine mice. Values for Penh in cohorts that were inoculated with vehicle alone were no different from those for SeV-UV treatment (data not shown). *Significant increase from control mice that received SeV-UV. **Significant increase from control mice and from SeV-infected ICAM-1-/- mice.

\section{Figure 2}

ICAM-1 deficiency protects against weight loss after viral infection without changing viral clearance. Wild-type and ICAM-1-null mice were inoculated with $\mathrm{SeV}\left(5,000 \mathrm{EID}_{50}\right)$ and analyzed as follows. (a) Body weights relative to initial values were determined as mean \pm SEM of eight mice. ${ }^{*}$ Significant increase compared with the wild-type cohort. (b) Lungs were subjected to Western blotting against anti-SeV $\mathrm{Ab}$, and bands corresponding to $\mathrm{SeV}$ nucleocapsid protein (NP) and the Sp 1 control were quantified by densitometry as mean \pm SEM of three mice. (c and $\mathbf{d}$ ) Lungs were also assayed for $\mathrm{SeV}$ plaque-forming units (c) and SeV copy number (d). Values for viral plaque-forming units and viral RNA copy number represent mean \pm SEM for $1 \mathrm{~g}$ of lung tissue and $100 \mathrm{ng}$ of total lung RNA, respectively (three mice/genotype). Viral RNA copy number was determined by real-time RT-PCR for SeV nucleocapsid protein and corrected for GAPDH control. For a-d, values obtained from $+/+$ and $-/-$ cohorts inoculated with PBS or UV-inactivated $\mathrm{SeV}$ were no different from preinoculation values (data not shown).

Indeed, airway hyperreactivity developed in concert with prominent airway epithelial remodeling that was fully manifest by 21 days and was maintained to a similar degree at 77 days after $\mathrm{SeV}$ infection in wildtype or ICAM-1-null mice (Figure 4). In particular, we observed a marked increase in PAS-positive cell staining in a pattern indicative of goblet cell hyperplasia in the airway epithelium. The increase in PAS-positive cells was matched by increased immunostaining for the mucin MUC5AC, indicating upregulation of mucus-producing goblet cells. Quantifying this phenotype confirmed that ICAM-1 deficiency was not protective against chronic goblet cell hyperplasia, just as it was not protective against long-term airway hyperreactivity. However, in the case of goblet cell hyperplasia, ICAM-1 deficiency did not exert even transient protection at 21 days after $\mathrm{SeV}$ infection,

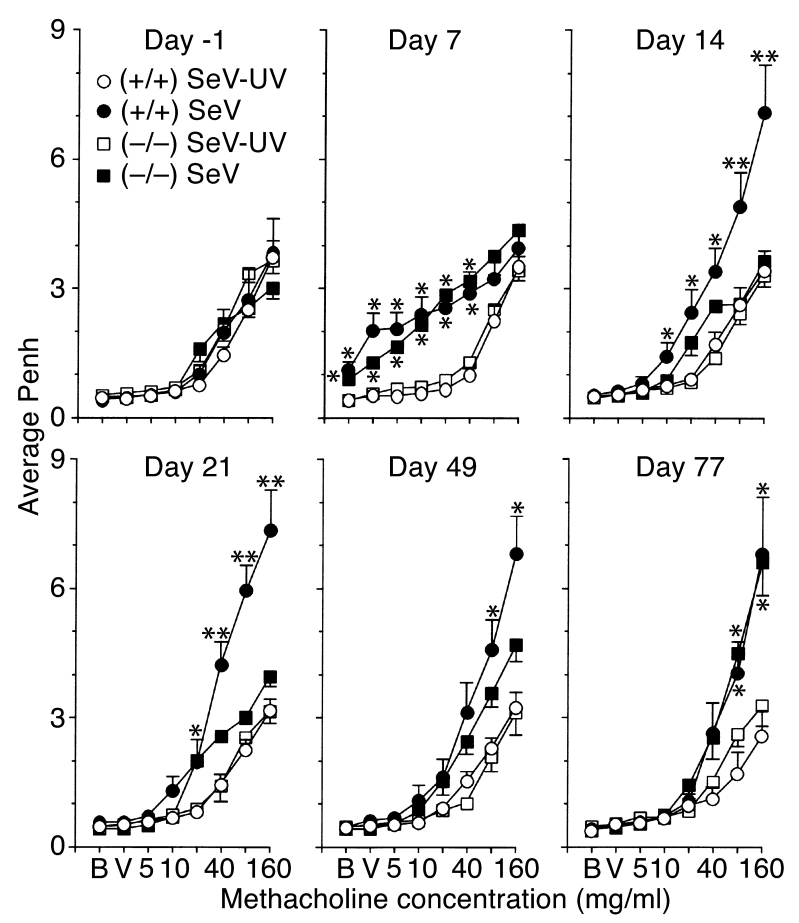



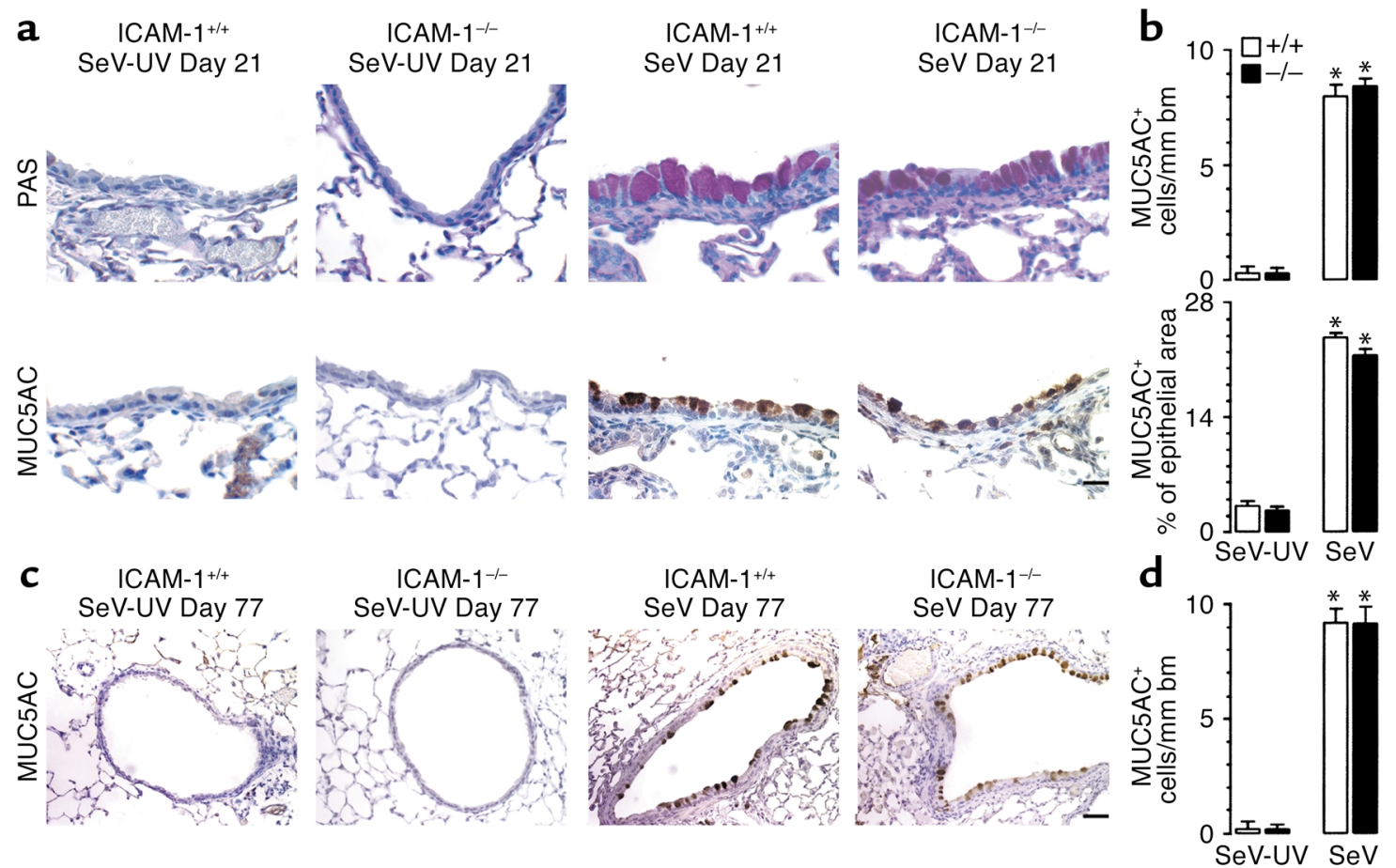

\begin{abstract}
Figure 4
Persistence of goblet cell hyperplasia after viral infection in wild-type and ICAM-1-null mice. (a) Wild-type and ICAM-1-null mice were inoculated with SeV (5,000 EID 50$)$ or SeV-UV, and lung sections were stained with PAS and immunostained for MUC5AC mucin. Representative photomicrographs are shown for each genotype $(n=5)$ at postinoculation day 21. Immunostaining with nonimmune $\lg G$ gave no signal above background (data not shown). Bar, $20 \mu \mathrm{m}$. (b) Quantification of results shown in a using values for MUC5AC ${ }^{+}$cells per $\mathrm{mm}$ basement membrane $(\mathrm{bm})$ and for MUC5AC staining as percentage of total epithelial area. Values represent mean $\pm \mathrm{SEM}(n=10$ airways from three to five mice). Similar results were found by analysis of staining intensity (data not shown). (c) Wild-type and ICAM-1-null mice were inoculated with SeV or SeV-UV and subjected to analysis on postinoculation day 77 as described in $\mathbf{a}$ and $\mathbf{b}$. Representative photomicrographs and corresponding quantification are shown for MUC5AC immunostaining for each genotype $(n=5)$. Bar, $50 \mu \mathrm{m}$. Results for PAS staining were similar to results at postinoculation day 21 (data not shown). (d) Quantification of results shown in $\mathbf{c}$. Values represent mean \pm SEM. No significant difference was detected for postinfection values for wild-type versus ICAM-1-null or for postinfection day 21 versus day 77 . *Significant increase from control SeV-UV.
\end{abstract}

suggesting separate controls for the development of the two components (hyperreactivity and remodeling) of the chronic asthma phenotype as well.

$I F N-\gamma^{\prime-}$ mice and wild-type mice exhibit similar acute and chronic responses. As noted above, epithelial ICAM-1 gene expression is selectively sensitive to IFN- $\gamma$ in vitro and in vivo, but is still sensitive to viral induction in vitro using epithelial monolayers that exclude IFN- $\gamma$-producing cell types $(27,36,47,57-59)$. Thus, the relative roles of IFN- $\gamma$ (derived from immune cells) versus other endogenous mediators produced directly by epithelial cells for driving ICAM-1 expression in vivo were still undefined. In the present experiments, we found that viral induction of ICAM-1 expression proceeded unchanged in IFN- $\gamma$-null mice, suggesting that epithelial pathways for ICAM-1 expression respond directly to viral infection without a requirement for IFN- $\gamma$ that is derived from immune cells. In addition, IFN- $\gamma$-null mice exhibited levels of weight loss, mortality, viral protein, and airway inflammation that were no different from those in wild-type control mice (Figure 5, a and b, and data not shown). These findings are consistent with the preservation of the CTL response and normal SeV clearance in the absence of IFN- $\gamma$ in the BALB/cJ genetic background (52). The correlation between ICAM-1 expression, airway inflammation, and airway reactivity was reinforced in these experiments when we found that wild-type and IFN- $\gamma$-null mice both exhibited similar increases in acute and chronic airway reactivity as well (Figure 5c). In both cohorts, airway hyperreactivity was maintained at the same levels for at least a year after viral clearance, in concert with the same persistent degree of goblet cell hyperplasia (Figure 6, a and b).

Comparison to the allergic response. To determine whether the virus-induced phenotype was typical of other asthmagenic stimuli, we next monitored the airway response to allergen over an extended time period in this setting. We used a protocol that depended on allergen sensitization and subsequent challenge with Ova, since that allergen has been so extensively studied in murine models of asthma. In the present experiments, Ova challenge caused smaller increases in airway reactivity but a similar degree of goblet cell hyperplasia compared with viral 


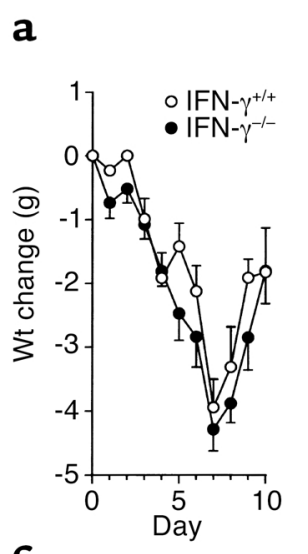

c

b

Day 0

Day 3
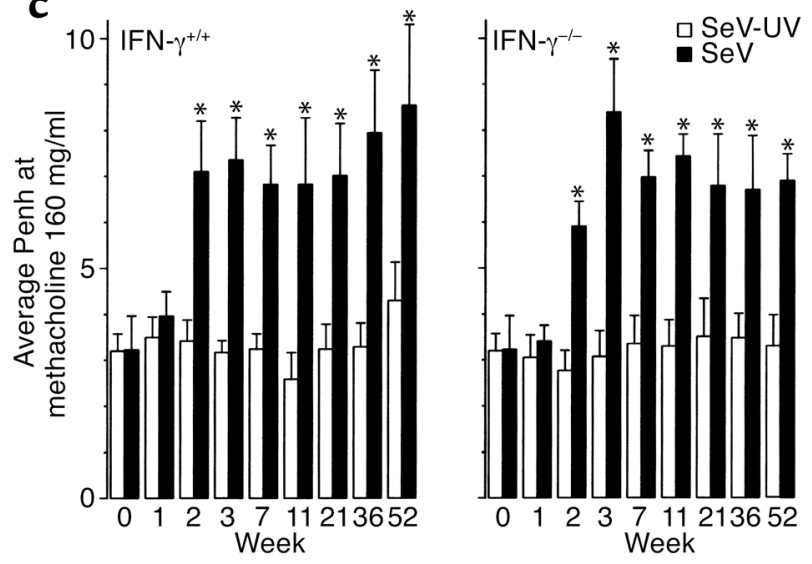

infection (Figure 7). However, in contrast to the response to viral infection, allergen-induced phenotypes were fully developed by day 3 after challenge, were decreasing by day 21 , and were resolved by day 77. These observations were consistent with previous studies of Ova immunization and challenge in mice $(45,46,60)$, but the present data provide a more complete description for the resolution of the allergic

\section{Figure 5}

IFN- $\gamma$-null and wild-type mice exhibit the same acute and chronic responses to viral infection. Wild-type $(+/+)$ and IFN- $\gamma$-null (-/-) mice were inoculated with $\mathrm{SeV}\left(5,000 \mathrm{EID}_{50}\right)$ and analyzed as follows. (a) Body weights relative to initial values were determined as mean \pm SEM of eight to ten mice per group. No significant difference was found for wild-type versus IFN- $\gamma$-null cohorts. (b) Lung sections from IFN- $\gamma$-null mice were immunostained with anti-SeV Ab and counterstained with hematoxylin on the indicated postinoculation days. Representative photomicrographs are shown for each genotype (five mice/genotype). Bar, $20 \mu \mathrm{m}$. (c) Airway reactivity to inhaled methacholine was assessed at the indicated times before and after inoculation with $\mathrm{SeV}$ $\left(5,000 \mathrm{EID}_{50}\right)$ or SeV-UV as described in Figure 3 legend. Values are shown for the final concentration of methacholine $(160 \mathrm{mg} / \mathrm{ml})$ and represent mean \pm SEM of nine mice. The same pattern was observed at lower concentrations of methacholine, and the values for Penh in wild-type or IFN- $\gamma^{-1}$ cohorts that received no virus were no different from those for SeV-UV (data not shown). *Significant increase compared with control mice that received SeV-UV.

response. In addition, the present results for Ova and $\mathrm{SeV}$ derive from mice of the same genetic background (C57BL/6J) to exclude the possibility that this was the basis for short- versus long-term effects of allergen versus viral infection.

Response to treatment with glucocorticoid. Previous work has indicated that asthma and allergen-induced asthma in experimental models is sensitive to glucocorticoid treatment $(24,60)$. Accordingly, we next determined whether the virus-induced asthma phenotypes were responsive to glucocorticoid treatment. Using a protocol for glucocorticoid administration that began after viral clearance but before airway remodeling, we found that the chronic remodeling/hyperreactivity phenotype was at least partially prevented by treatment with glucocorticoids (Figure 8 , $a$ and $b$ ). As discussed below, these findings are consistent with similar events in glucocorticoidtreated subjects with asthma.

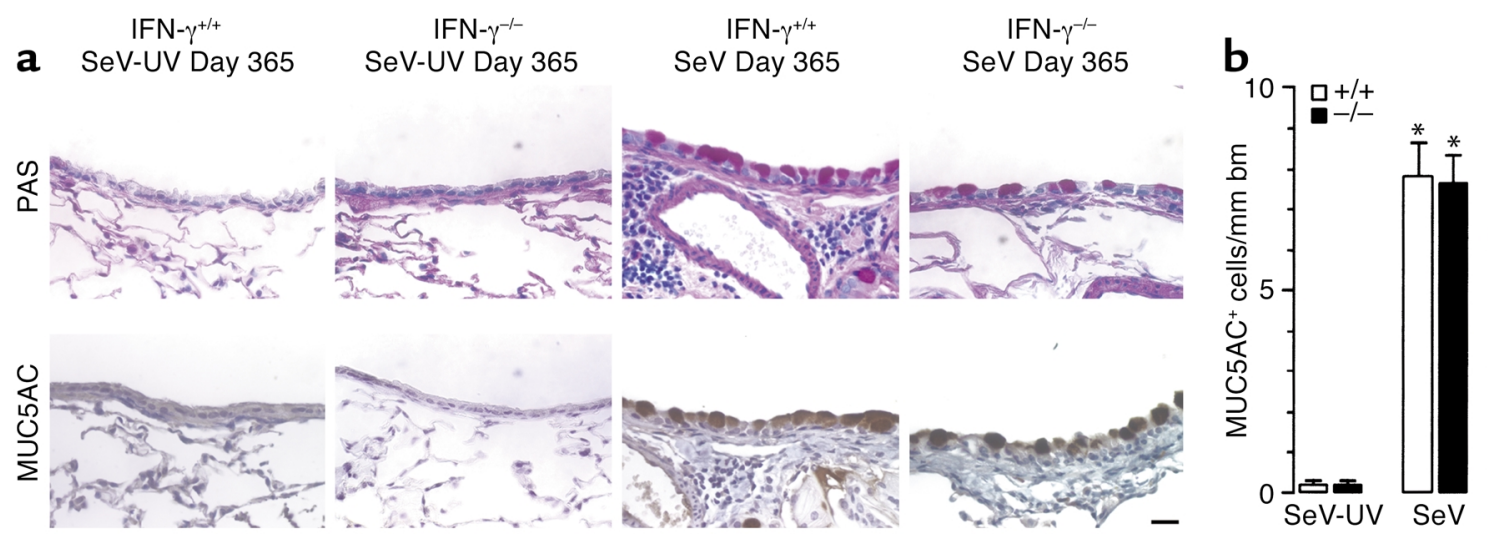

Figure 6

Long-term persistence of goblet cell hyperplasia after viral infection in wild-type and IFN- $\gamma$-null mice. (a) Wild-type and IFN- $\gamma$-null mice were inoculated with $\mathrm{SeV}\left(5,000 \mathrm{EID}_{50}\right)$ or SeV-UV, and lung sections were stained for PAS and MUC5AC mucin as described in Figure 4 legend. Representative photomicrographs are shown for each genotype and condition $(n=5)$ at postinoculation day 365 . Bar, 20 $\mu \mathrm{m}$. (b) Quantification of results shown in a. Values represent mean \pm SEM. The response of IFN- $\gamma$-null mice was no different from that of wild-type mice. * Significant change from control SeV-UV treatment. 

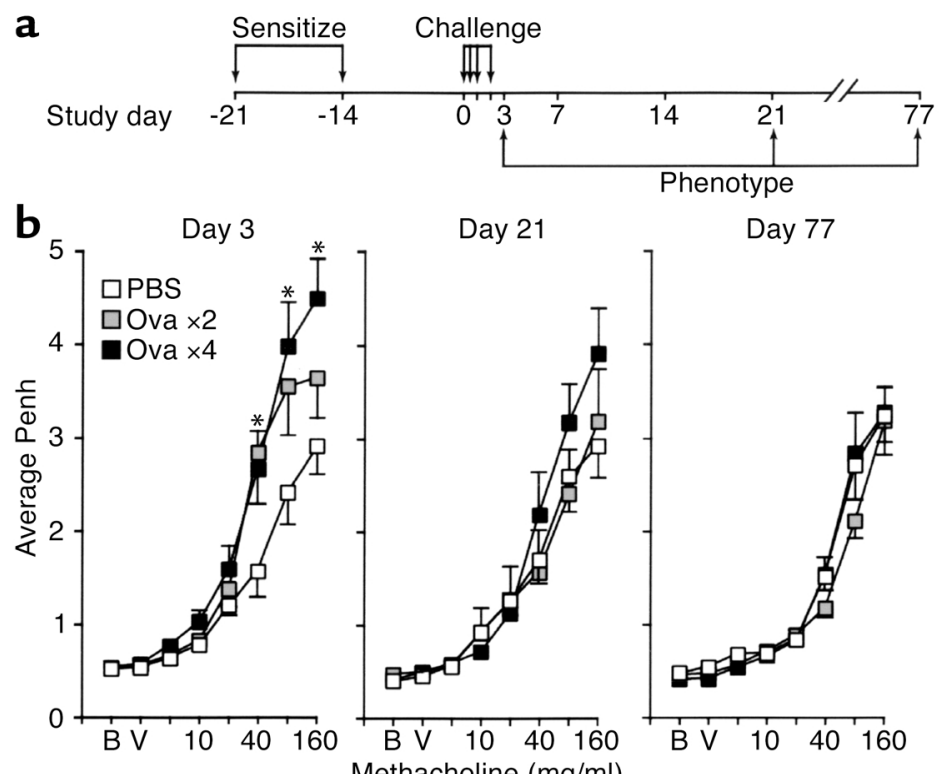

C Day 3

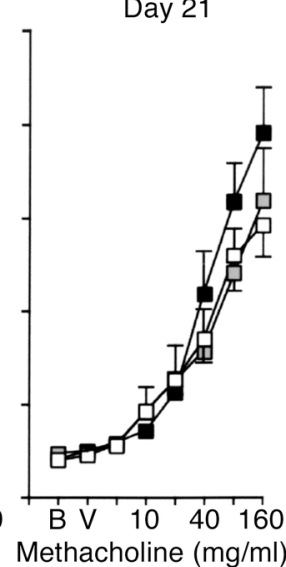

Day 77

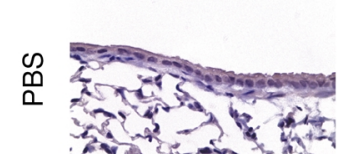

Day 21
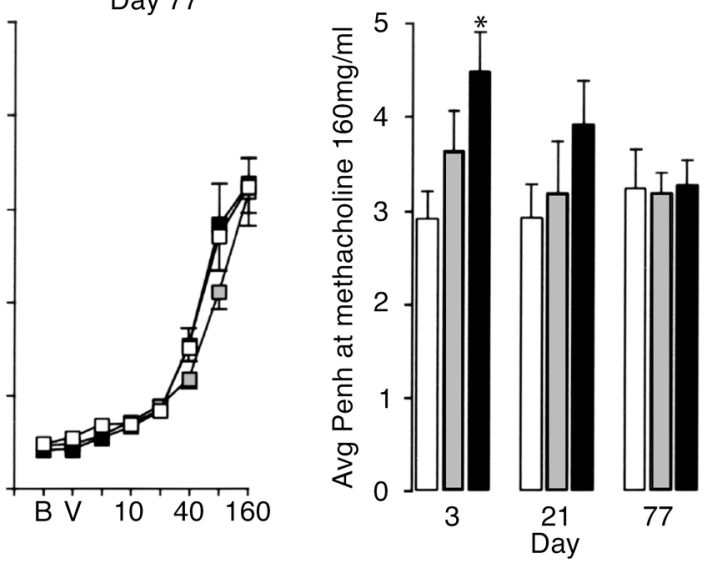

Day 77
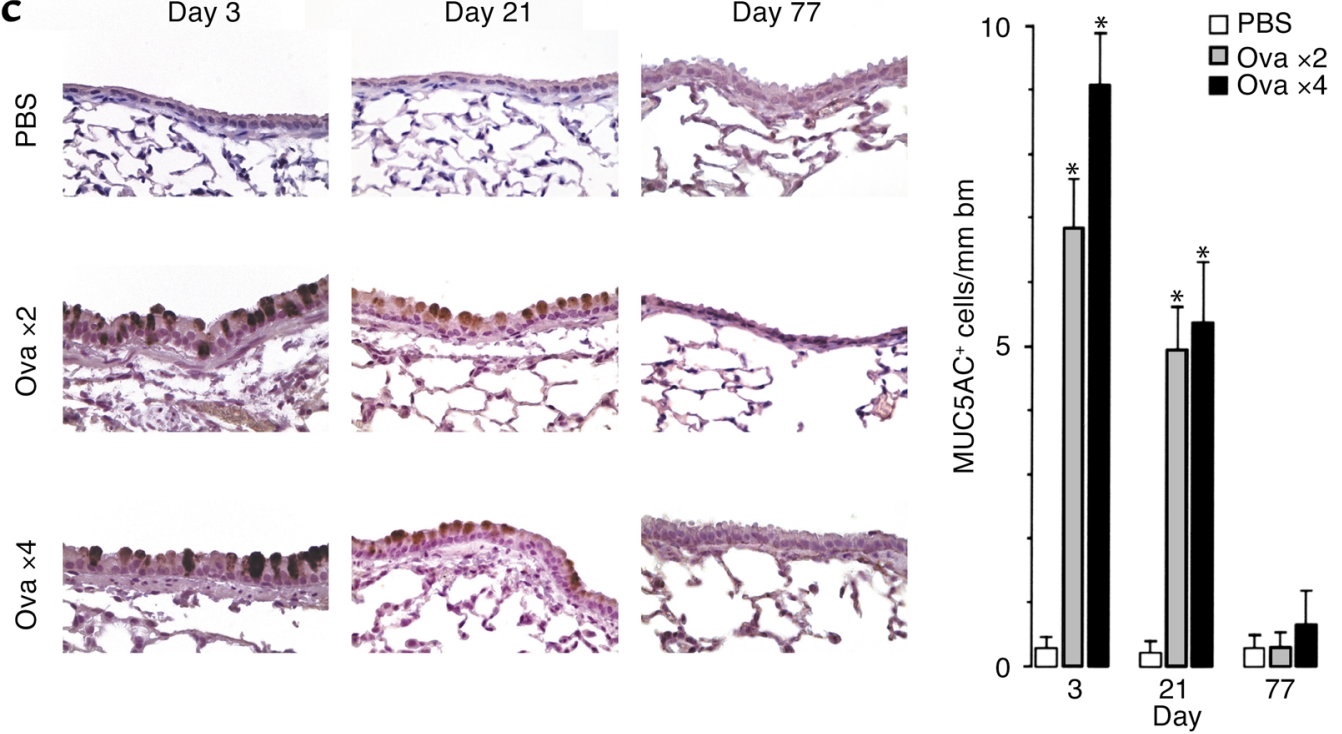

Figure 7

Reversibility of airway hyperreactivity and goblet cell hyperplasia after allergen challenge. (a) On the indicated study days, wild-type mice were sensitized to Ova, then challenged with intranasal PBS or Ova either twice on day 0 (Ova $\times 2)$ or twice on day 0 and again on days 1 and 2 (Ova $\times 4$ ), and finally were phenotyped for airway hyperreactivity and goblet cell hyperplasia. (b) For each experimental condition, airway reactivity was assessed as described in legends for Figure 3 and Figure 5. (c) For the same conditions, lung sections were immunostained for MUC5AC mucin, and immunopositive cells were quantified as described in Figure 4 legend. For $\mathbf{b}$ and $\mathbf{c}$, all values represent mean \pm SEM for groups of eight to ten mice. *Significant change from the corresponding PBS-challenged cohort.

\section{Discussion}

We reported previously that asthma is characterized by persistent activation of the bronchial epithelium in a pattern that is similar to one inducible by viral infection $(28,30,31)$. These findings suggested that an abnormal response to virus might contribute to asthma pathogenesis (reviewed in ref. 26), but it was also possible that the epithelial response was driven by other inflammatory stimuli. For example, allergen inhalation might also lead to epithelial activation indirectly via Th cell cytokine production, and under some circumstances even this response may require Th1 cytokines that are more typical of anti-viral responses $(15,61)$. In addition, the previous data focused on the acute immune response to virus and so could not fully account for the persistent changes in epithelial behavior that occur in a chronic disease such as asthma. In that context, the present study offers the critical information that a single paramyxoviral infection has the capacity to cause not only the acute manifestations of the asthma phenotype but also results in long-lasting changes in airway behavior that are characteristic of asthma. In addition, we demonstrate that the acute and chronic responses can be genetically segregated, since the acute but not the 

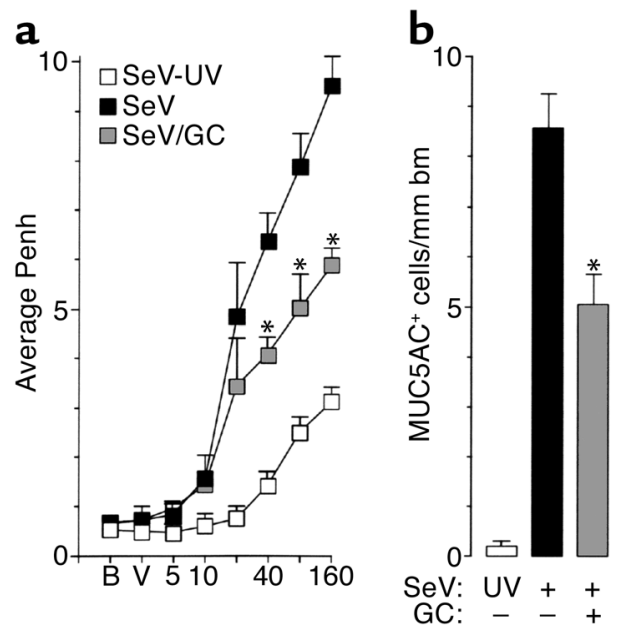

Figure 8

Glucocorticoid suppression of airway hyperreactivity and goblet cell hyperplasia after viral infection in mice. (a) Wild-type mice were inoculated with $\mathrm{SeV}\left(5,000 \mathrm{EID}_{50}\right)$ or SeV-UV and then treated with saline or dexamethasone $(0.5 \mathrm{mg} / \mathrm{kg}$ per day, given subcutaneously) on postinoculation days 13-21. At the end of this period, levels of airway reactivity were determined as described in Figure 3 legend. (b) For the same conditions described in a, MUC5AC+ cells were determined as described in Figure 4 legend. For $\mathbf{a}$ and $\mathbf{b}$, all values represent mean \pm SEM. $n=10$ mice. * Significant decrease compared with saline-treated cohort. GC, glucocorticoid.

chronic response depends on the expression of the ICAM-1 gene and so is lost in the ICAM-1-null mouse. Thus, specific host defense genes participate in mediating the acute inflammatory but not necessarily the chronic remodeling response to viral infection. As discussed below, the present findings suggest overlap in the underlying mechanism for the paramyxoviral response in mice and the phenotype in asthma.

In particular, the present study also addresses the role of persistent infection and cytokine bias in the development of the chronic asthma phenotype after viral infection. For example, others have indicated that the loss of IFN- $\gamma$ production may underlie the longer lasting hyperreactivity and airway fibrosis that develops in susceptible strains of rats after viral infection $(62,63)$. Based on this model and others as well as studies of tissue from human subjects, it has been suggested that viral persistence may drive the asthma phenotype in children (64). It has also been suggested that diminished IFN- $\gamma$ production and decreased exposure to immune agents that stimulate this response may underlie the rising incidence of childhood asthma $(65,66)$. However, we show that acute and chronic postviral phenotypes develop in the same manner in IFN- $\gamma$-deficient mice of analogous age. These findings are consistent with our previous results indicating that airway mucosal tissue in asthmatic subjects exhibits no difference from the normally low levels of IFN- $\gamma$ or IFN- $\gamma$-producing cells found in healthy subjects (30). We also precisely determined the tissue levels of replicating virus and viral genome, and similar to other reports, found no evidence of chronic infection or persistence of defective virus. Thus, while some riboviruses may persist in tissue as low-level quasi species (54), in the present case, $\mathrm{SeV}$ was eliminated from airway tissue by 12-21 days after infection. The results suggest a hit-and-run hypothesis for the viral effect, i.e., transient infection causes permanent alteration in host cell behavior. This type of mechanism has been proposed for oncogenic DNA viruses, but has not yet been observed for nononcogenic riboviruses $(38,39)$. Further proof of this possibility will depend on identifying specific viral gene products responsible for altering host gene expression and consequent phenotype.

In that regard, we note that the capacity to develop two postviral chronic phenotypes, goblet cell hyperplasia and airway reactivity, can be separated in the host genetic background used in the present study. Thus, at 21 days after infection, the epithelial phenotype is fully manifest, whereas the chronic hyperreactivity is not yet present. At this timepoint, the reactivity is still subject to influence by ICAM-1 gene expression and presumably acute, ICAM-1-dependent inflammation. By contrast, the recurrence of reactivity in the ICAM-1-null mouse at later timepoints suggests that this phenotype is regulated by distinct genetic controls independent of this acute response. The present findings therefore support a scheme in which replicating virus causes direct induction of epithelial immune-response gene expression, and this leads to inflammation and inflammation-dependent hyperreactivity in the first few weeks after infection. However, additional genetic analysis will be needed to determine how these chronic phenotypes segregate in mice and in humans and to define the relevant genes for susceptibility at each timepoint.

The present effects of viral infection are distinct from the more transient impact of antigen sensitization/ exposure even after repeated challenges (67). In addition, the allergic response appears to be more sensitive to regulation by Th cytokines, notably IFN- $\gamma(3,68)$. However, in both allergen challenge and viral infection, the remodeling/hyperreactivity phenotype is at least partially prevented by treatment with glucocorticoids, whether initiated after significant viral clearance (but before remodeling) or during allergen challenge and remodeling (67). As noted above, the results suggest a hit-and-run hypothesis for the viral effect, but even so, there must be some element of memory in the host tissue so the phenotype can be preserved. Several possibilities exist for this type of memory, but in the setting of viral infection, a conspicuous candidate is the persistence of virus-specific $T$ cells in the lungs $(69,70)$. Subsets of this population, e.g., $\mathrm{CD}^{+} \mathrm{T}$ cells, have been variously incriminated as downregulating and upregulating the Th2 features of the acute anti-viral response (71-73). The role of these cells in the chronic response to viral infection still needs to be determined, but the sensitivity of $\mathrm{T}$ cells to glucocorticoid action reinforces their candidacy for involvement (74). As noted above, 
however, these studies have focused on the acute response to virus, and the relevance of this mechanism for chronic persistent changes must still be defined.

Taken together, the present findings establish the capacity of a single paramyxoviral infection to permanently change epithelial behavior and airway reactivity in a pattern that is remarkably similar to one in asthma. The present results add to previous findings indicating that paramyxoviral infection and asthma may activate a network of epithelial immune-response genes that are part of the innate immune response $(28,30,31)$. Thus, we now find that paramyxoviral infection may also lead to chronically abnormal airway structure and function, with goblet cell hyperplasia and airway hyperreactivity that is typical of asthma and other hypersecretory airway diseases. Furthermore, this chronic phenotype can be genetically segregated from the acute anti-viral response in mice. Several gene products appear to regulate goblet cell hyperplasia after allergen exposure, fitting a paradigm in which Th2 products (e.g., IL-4, IL-5, IL-9, and IL-13) may upregulate while Th1 products (e.g., IFN- $\gamma$ ) downregulate the response $(75,76)$. Further studies will be required to precisely identify the genes responsible for epithelial remodeling and chronic hyperreactivity in response to paramyxoviral infection, but the lack of IFN- $\gamma$-dependent regulation in this setting implies that the viral pathway is distinct from pathways driven by allergen. Indeed, the present results raise the possibility that primary paramyxoviral infection in a specific genetic background may lead to chronic dysfunction of host cell behavior that overlaps with but does not depend on allergy (26).

\section{Acknowledgments}

The authors gratefully acknowledge Robert Arch, Guang Fan, Michelle Jenkerson, Peter Karanja, William Roswit, and Holly Toennies for assistance and advice. This research was supported by grants from NIH (Heart, Lung, and Blood Institute), the American Lung Association, the Martin Schaeffer Fund, and the Alan A. and Edith L. Wolff Charitable Trust.

1. Webb, D.C., et al. 2000. Integrated signals between IL-13, IL-4, and IL-5 regulate airways hyperreactivity. J. Immunol. 165:108-113.

2. Temann, U.-A., Ray, P., and Flavell, R.A. 2002. Pulmonary overexpression of IL-9 induces Th2 cytokine expression, leading to immune pathology. J. Clin. Invest. 109:29-39. doi:10.1172/JCI200213696.

3. Lack, G., et al. 1996. Nebulized IFN-gamma inhibits the development of secondary allergic responses in mice. J. Immunol. 157:1432-1439.

4. Gavett, S.H., et al. 1995. Interleukin 12 inhibits antigen-induced airway hyperresponsiveness, inflammation, and Th2 cytokine expression in mice. J. Exp. Med. 182:1527-1536.

5. Sur, S., et al. 1999. Long term prevention of allergic lung inflammation in a mouse model of asthma by $\mathrm{CPG}$ oligodeoxynucleotides. J. Immunol. 162:6284-6293.

6. Finotto, S., et al. 2002. Development of spontaneous airway changes consistent with human asthma in mice lacking T-bet. Science. 295:336-338.

7. Burrows, B., Martinez, F.D., Halonen, M., Barbee, R.A., and Cline, M.G. 1989. Association of asthma with serum IgE levels and skin-test reactivity to allergens. N. Engl. J. Med. 320:271-277.

8. Ying, S., Durham, S.R., Corrigan, C.J., Hamid, Q., and Kay, A.B. 1995 Phenotype of cells expressing mRNA for TH2-type (interleukin 4 and interleukin 5) and TH1-type (interleukin 2 and interferon gamma) cytokines in bronchoalveolar lavage and bronchial biopsies from atopic asthmatic and normal control subjects. Am. J. Respir. Cell Mol. Biol. 12:477-487.
9. Kay, A.B. 2001. Allergy and allergic diseases. N. Engl. J. Med. 344:30-37. 10. Ober, C., and Moffatt, M.F. 2000. Contributing factors to the pathobiology. The genetics of asthma. Clin. Chest Med. 21:245-261.

11. Broide, D.H., et al. 1991. Evidence of ongoing mast cell and eosinophil activation in symptomatic asthma airway. J. Allergy Clin. Immunol. 88:637-648.

12. Poston, R.N., et al. 1992. Immunohistochemical characterization of the cellular infiltration in asthmatic bronchi. Am. Rev. Respir. Dis. 145:918-921.

13. Williams, C.M.M., and Galli, S.J. 2000. Mast cells can amplify airway reactivity and features of chronic inflammation in an asthma model in mice. J. Exp. Med. 192:455-462.

14. Bandeira-Melo, C., Herbst, A., and Weller, P.F. 2001. Eotaxins. Contributing to the diversity of eosinophil recruitment and activation. Am. J. Respir. Cell Mol. Biol. 24:653-657.

15. Randolph, D.A., Stephens, R., Carruthers, C.J.L., and Chaplin, D.D. 1999. Cooperation between Th1 and Th2 cells in a murine model of eosinophilic airway inflammation. J. Clin. Invest. 104:1021-1029.

16. Hansen, G., Berry, G., DeKruyff, R., and Umetsu, D. 1999. Allergen-specific Th1 cells fail to counterbalance Th2 cell-induced airway hyperreactivity but cause severe airway inflammation. J. Clin. Invest. 103:175-183.

17. Wills-Karp, M., et al. 1998. Interleukin-13: central mediator of allergic asthma. Science. 282:2258-2261.

18. Melhop, P.D., et al. 1997. Allergen-induced bronchial hyperreactivity and eosinophilic inflammation occur in the absence of IgE in a mouse model of asthma. Proc. Natl. Acad. Sci. USA. 94:1344-1349.

19. Hogan, S.P., Mould, A., Kikutani, H., Ramsay, A.J., and Foster, P.S. 1997. Aeroallergen-induced eosinophilic inflammation, lung damage, and airways hyperreactivity in mice can occur independently of IL-4 and allergen-specific immunoglobulins. J. Clin. Invest. 99:1329-1339.

20. Foster, P.S., Hogan, S.P., Ramsay, A.J., Matthaei, K.I., and Young, I.G. 1995. IL-5 deficiency abolishes eosinophilia, airways hyperreactivity, and lung damage in a mouse asthma model. J. Exp. Med. 183:195-201.

21. Corry, D.B., et al. 1995. Interleukin 4, but not interleukin 5 or eosinophils, is required in a murine model of acute airway hyperreactivity. J. Exp. Med. 183:109-117.

22. Holtzman, M.J., Sampath, D., Castro, M., Look, D.C., and Jayaraman, S. 1996. The one-two of T helper cells: does interferon-gamma knock out the Th2 hypothesis for asthma? Am. J. Respir. Cell Mol. Biol. 14:316-318.

23. Hakonarson, H., et al. 2001. Allelic frequencies and patterns of singlenucleotide polymorphisms in candidate genes for asthma and atopy in Iceland. Am. J. Respir. Crit. Care Med. 164:2036-2044.

24. Grayson, M.H., and Holtzman, M.J. 2002. Lessons from allergic rhinitis versus asthma pathogenesis and treatment. Immunol. Allergy Clin. North Am. In press.

25. Drazen, J.M., Arm, J.P., and Austen, K.F. 1996. Sorting out the cytokines of asthma. J. Exp. Med. 183:1-5.

26. Holtzman, M.J., et al. 2002. Immunity, inflammation, and remodeling in the airway epithelial barrier: epithelial-viral-allergic paradigm. Physiol. Rev. 82:19-46.

27. Look, D.C., et al. 1998. Direct suppression of Stat 1 function during adenoviral infection. Immunity. 9:871-880.

28. Taguchi, M., et al. 1998. Patterns for RANTES secretion and intercellular adhesion molecule-1 expression mediate transepithelial $T$ cell traffic based on analyses in vitro and in vivo. J. Exp. Med. 187:1927-1940.

29. Koga, T., et al. 1999. Virus-inducible expression of a host chemokine gene relies on replication-linked mRNA stabilization. Proc. Natl. Acad. Sci. USA. 96:5680-5685.

30. Sampath, D., Castro, M., Look, D.C., and Holtzman, M.J. 1999. Constitutive activation of an epithelial signal transducer and activator of transcription (Stat1) pathway in asthma. J. Clin. Invest. 103:1353-1361.

31. Walter, M.J., Kajiwara, N., Karanja, P., Castro, M., and Holtzman, M.J. 2001. IL-12 p40 production by barrier epithelial cells during airway inflammation. J. Exp. Med. 193:339-352.

32. Collins, P.L., Chanock, R.M., and McIntosh, K. 1996. Parainfluenza viruses. In Fields virology. B.N. Fields, D.M. Knipe, and P.M. Howley, editors. Lippincott Williams \& Wilkins. Philadelphia, Pennsylvania, USA. 1205-1241.

33. Domachowske, J.B., and Rosenberg, H.F. 1999. Respiratory syncytial virus infection: immune response, immunopathogenesis, and treatment. Clin. Microbiol. Rev. 12:298-309.

34. Sigurs, N. 2001. Epidemiologic and clinical evidence of a respiratory syncytial virus-reactive airway disease link. Am. J. Respir. Crit. Care Med. 163(Suppl.):S2-S6.

35. Ahmed, R., Morrison, L.A., and Knipe, D.M. 1996. Persistence of viruses. In Fields virology. B.N. Fields, D.M. Knipe, and P.M. Howley, editors. Lippincott Williams \& Wilkins. Philadelphia, Pennsylvania, USA. 219-249.

36. Nakajima, S., Look, D.C., Roswit, W.T., Bragdon, M.J., and Holtzman, M.J. 1994. Selective differences in vascular endothelial- vs. airway epithelial-T cell adhesion mechanisms. Am. J. Physiol. 267:L422-L432. 
37. Nakajima, S., Roswit, W.T., Look, D.C., and Holtzman, M.J. 1995. A hierarchy for integrin expression and adhesiveness among $\mathrm{T}$ cell subsets that is linked to TCR gene usage and emphasizes $\mathrm{V}$ delta 1+ gamma delta $\mathrm{T}$ cell adherence and tissue retention. J. Immunol. 155:1117-1131.

38. Shen, Y., Zhu, H., and Shenk, T. 1997. Human cytomegalovirus IE1 and IE2 proteins are mutagenic and mediate "hit and run" oncogenic transformation in cooperation with the adenovirus E1A proteins. Proc. Natl. Acad. Sci. USA. 94:3341-3345.

39. Nevels, M., Tauber, B., Spruss, T., Wolf, H., and Dobner, T. 2001. "Hit and run” transformation by adenovirus oncogenes. J. Virol. 75:3089-3094.

40. Dalton, D.K., et al. 1993. Multiple defects of immune cell function in mice with disrupted interferon-gamma genes. Science. 259:1739-1742.

41. Xu, H., et al. 1994. Leukocytosis and resistance to septic shock in intercellular adhesion molecule 1-deficient mice. J. Exp. Med. 180:95-109.

42. King, P.D., et al. 1995. Novel isoforms of murine intercellular adhesion molecule- 1 generated by alternative RNA splicing. J. Immunol. 154:6080-6093.

43. Sugita, K., Maru, M., and Sato, K. 1974. A sensitive plaque assay for Sendai virus in an established line of monkey kidney cells. Jpn. J. Microbiol. 18:262-264.

44. Alimam, M.Z., et al. 2000. Muc-5/5ac mucin messenger RNA and protein expression is a marker of goblet cell metaplasia in murine airways. Am. J. Respir. Cell Mol. Biol. 22:253-260.

45. Hamelmann, E., et al. 1997. Measurement of airway responsiveness in allergic mice using barometric plethysmography. Am. J. Respir. Crit. Care Med. 156:766-775.

46. Kung, T.T., et al. 1993. Characterization of a murine model of allergic pulmonary inflammation. Int. Arch. Allergy Immunol. 105:83-90.

47. Look, D.C., Keller, B.T., Rapp, S.R., and Holtzman, M.J. 1992. Selective induction of intercellular adhesion molecule- 1 by interferon-gamma in human airway epithelial cells. Am. J. Physiol. 263:L79-L87.

48. Gonzalo, J.-A., et al. 1996. Eosinophil recruitment to the lung in a murine model of allergic inflammation. J. Clin. Invest. 98:2332-2345.

49. Bullard, D.C., et al. 1995. P-selectin/ICAM-1 double mutant mice: acute emigration of neutrophils into the peritoneum is completely absent but is normal into pulmonary alveoli. J. Clin. Invest. 95:1782-1788.

50. O'Brien, A.D., Standiford, T.J., Bucknell, K.A., Wilcoxen, S.E., and Paine, R.I. 1999. Role of alveolar epithelial cell intercellular adhesion molecule1 in host defense against Klebsiella pneumoniae. Am. J. Physiol. 276:L961-L970.

51. Hou, S., Doherty, P.C., Zijlstra, M., Jaenisch, R., and Katz, J.M. 1992. Delayed clearance of Sendai virus in mice lacking class I MHC-restricted CD8+ T cells. J. Immunol. 149:1319-1325.

52. Mo, X.Y., Tripp, R.A., Sangster, M.Y., and Doherty, P.C. 1997. The cytotoxic T-lymphocyte response to Sendai virus is unimpaired in the absence of gamma interferon. J. Virol. 71:1907-1910.

53. Zhong, W., Marshall, D., Coleclough, C., and Woodland, D.L. 2000 $\mathrm{CD} 4+\mathrm{T}$ cell priming accelerates the clearance of Sendai virus in mice, but has a negative effect on CD8 $+\mathrm{T}$ cell memory. J. Immunol. 164:3274-3282.

54. Farci, P., et al. 2000. The outcome of acute hepatitis $\mathrm{C}$ predicted by the evolution of the viral quasispecies. Science. 288:339-343.

55. Holtzman, M.J., et al. 1983. Importance of airway inflammation for hyperresponsiveness induced by ozone in dogs. Am. Rev. Respir. Dis. 127:686-690.

56. Folkerts, G., Busse, W.W., Nijkamp, F., Sorkness, R., and Gern, J.E. 1998 Virus-induced airway hyperresponsiveness and asthma. Am.J. Respir. Crit. Care Med. 157:1708-1720.

57. Look, D.C., Pelletier, M.R., and Holtzman, M.J. 1994. Selective interaction of a subset of interferon-gamma response element binding proteins with the intercellular adhesion molecule-1 (ICAM-1) gene promoter controls the pattern of expression on epithelial cells. J. Biol. Chem 269:8952-8958.

58. Look, D.C., Pelletier, M.R., Tidwell, R.M., Roswit, W.T., and Holtzman, M.J. 1995. Stat1 depends on transcriptional synergy with Sp1. J. Biol. Chem. 270:30264-30267.

59. Walter, M.J., Look, D.C., Tidwell, R.M., Roswit, W.T., and Holtzman, M.J. 1997. Targeted inhibition of interferon-gamma-dependent ICAM-1 expression using dominant-negative Stat1. J. Biol. Chem. 272:28582-28589.

60 . Blyth, D.I., et al. 1998. Induction, duration, and resolution of airway goblet cell hyperplasia in a murine model of atopic asthma: effect of concurrent infection with respiratory syncytial virus and response to dexamethasone. Am. J. Respir. Cell Mol. Biol. 19:38-54.

61. Castro, M., Walter, M.J., Chaplin, D.D., and Holtzman, M.J. 2000. Could asthma worsen by stimulating the Thelper type 1 (Th1) response? Am. J. Respir. Cell Mol. Biol. 22:143-146.

62. Bramley, A.M., Vitalis, T.Z., Wiggs, B.R., and Hegele, R.G. 1999. Effects of respiratory syncytial virus persistence on airway responsiveness and inflammation in guinea-pigs. Eur. Respir. J. 14:1061-1067.

63. Sorkness, R.L., Castleman, W.L., Kumar, A., Kaplan, M.R., and Lemanske, R.F.J. 1999. Prevention of chronic postbronchiolitis airway sequelae with IFN-gamma treatment in rats. Am. J. Repir. Crit. Care Med. 160:705-710.

64. Macek, V., Sorli, J., Koprivas, S., and Marin, J. 1994. Persistent adenoviral infection and chronic airway obstruction in children. Am. J. Respir. Crit. Care Med. 150:7-10.

65. Cookson, W.O.C.M. 1997. Asthma: an epidemic in the absence of infection. Science. 275:41-42.

66. Renzi, P.M., et al. 1999. Reduced interferon-gamma production in infants with bronchiolitis and asthma. Am. J. Respir. Crit. Care Med. 159:1417-1422.

67. Vanacker, J.J., Palmans, E., Kips, J.C., and Pauwels, R.A. 2001. Fluticasone inhibits but does not reverse allergen-induced structural airway changes. Am. J. Respir. Crit. Care Med. 163:674-679.

68. Coyle, A.J., et al. 1996. Mice lacking the IFN-gamma receptor have an impaired ability to resolve a lung eosinophilic inflammatory response associated with a prolonged capacity of T cells to exhibit a Th2 cytokine profile. J. Immunol. 156:2680-2685.

69. Hogan, R.J., et al. 2001. Activated antigen-specific CD8+ T cells persist in the lungs following recovery from respiratory virus infections. J. Immunol. 166:1813-1822.

70. Hogan, R.J., et al. 2001. Protection from respiratory virus infections can be mediated by antigen-specific CD4+ T cells that persist in the lungs. J. Exp. Med. 193:981-986.

71. Coyle, A.J., et al. 1995. Virus-specific CD8+ cells can switch to interleukin 5 production and induce airway eosinophilia. J. Exp. Med. 181:1229-1233.

72. Srikiatkhachorn, A., and Braciale, T.J. 1997. Virus-specific CD8+ T lymphocytes downregulate $T$ helper cell type 2 cytokine secretion and pulmonary eosinophila during experimental murine respiratory syncytial virus infection. J. Exp. Med. 186:421-432.

73. Schwarze, J., et al. 1999. CD8 T cells are essential in the development of respiratory syncytial virus-induced lung eosinophilia and airway hyperresponsiveness. J. Immunol. 162:4207-4211.

74. Ashwell, J.D., Lu, F.W.M., and Vacchio, M.S. 2000. Glucocorticoids in T cell development and function. Annu. Rev. Immunol. 18:309-345.

75. Cohn, L., Homer, R.J., Niu, N., and Bottomly, K. 1999. T helper 1 cells and interferon gamma regulate allergic airway inflammation and mucus production. J. Exp. Med. 190:1309-1317.

76. Wills-Karp, M. 2000. Trophic slime, allergic slime. Am. J. Respir. Cell Mol. Biol. 22:637-639. 